\title{
The dynamics of temperature extremes
}

\author{
Article
}

Accepted Version

Shepherd, T. G. (2015) The dynamics of temperature extremes. Nature, 522 (7557). pp. 425-427. ISSN 0028-0836 doi: https://doi.org/10.1038/522425a Available at https://centaur.reading.ac.uk/42921/

It is advisable to refer to the publisher's version if you intend to cite from the work. See Guidance on citing.

To link to this article DOI: http://dx.doi.org/10.1038/522425a

Publisher: Nature Publishing Group

All outputs in CentAUR are protected by Intellectual Property Rights law, including copyright law. Copyright and IPR is retained by the creators or other copyright holders. Terms and conditions for use of this material are defined in the End User Agreement.

\section{www.reading.ac.uk/centaur}

\section{CentAUR}

Central Archive at the University of Reading

Reading's research outputs online 
Climate science

The dynamics of temperature extremes

\section{Changes in the occurrence of atmospheric circulation patterns are not well understood. A study finds that these have been a big factor in observed changes in regional temperature extremes during recent decades. See Letter P.XXX}

Theodore G. Shepherd

The planet is unequivocally warming ${ }^{1}$, but the rate of warming varies in time and space. Although such variations are not unexpected, and do not challenge our grasp of the physics of global warming, understanding what drives them is crucial for predicting climate conditions at the regional scale. On page XXX of this issue, Horton et al. ${ }^{2}$ use a new analytical method to argue that, over many regions and seasons, changes in the occurrence of atmospheric circulation patterns have been a substantial driver of the observed changes in mid-latitude temperature extremes in the Northern Hemisphere over land for the past 35 years - increasing not only the likelihood of summertime heat waves in Europe, but also (since 1990) the occurrence of cold wintertime temperature extremes across central Asia ${ }^{3}$.

Identifying changes in climate extremes at the regional scale is hampered by the chaotic internal variability of the climate system, which adds a large degree of noise to the climate-change signal. Climate variability is manifested in changes in the occurrence of atmospheric circulation patterns, which can vary strongly from year to year, but can show trends over multi-decadal periods too. Such variations are also reflected in many climate extremes ${ }^{4}$. For example, European heat waves (Fig. 1) are more frequent when the 
summertime jet stream is 'blocked' from taking its usual path across the North Atlantic, because stagnant air over the continent can warm excessively through land-surface feedbacks ${ }^{5}$.

On top of this internal variability, climate change is itself expected to lead to changes in occurrence of atmospheric circulation patterns, although there is as yet little consensus on what these changes will be ${ }^{1}$. Both internal variability and the circulation response to climate change can lead to regional changes in temperature extremes that are larger or smaller - or even opposite to - that expected from global warming over extended time periods ${ }^{6}$.

To deal with the confounding effects of atmospheric circulation on changes in temperature extremes, Horton et al. applied a 'cluster' analysis to geopotential height fields — which map the heights needed to reach a given pressure, taking into account variations of surface pressure and atmospheric density - at an altitude of about $5 \mathrm{~km}$ to identify robust changes in the occurrence of circulation regimes. Their approach restricts the analysis to years after 1979, the period when observations from meteorological satellites improved the reliability of analysed changes in atmospheric circulation at mid-latitudes. But it avoids previously voiced concerns about the dangers of using subjective measures of atmospheric circulation ${ }^{7}$. The authors then partitioned observed changes in temperature extremes into those associated with changes in the occurrence of circulation regimes (dynamic changes), and those that have no such association (thermodynamic changes). This kind of partitioning is a growing theme in climate science ${ }^{8}$. 
Horton and colleagues find that most regions have experienced a clear increase in hot temperature extremes during summer since 1979. For roughly half those regions (eastern North America, Europe and western Asia), the researchers identify a substantial contribution to the observed trends (one-third to one-half) from the increased occurrence of anti-cyclonic circulations, which are associated with atmospheric blocking. The implication is that the tendency for increased summertime heat waves that can be expected from global warming has been substantially enhanced in these regions over the past 35 years by circulation changes that make heat waves more likely.

Although global warming suggests that, in general, the likelihood of cold temperature extremes should decrease, Horton et al. find an increase in wintertime cold temperature extremes over central Asia since 1990 - the period over which the extent of Arctic sea ice has rapidly declined. They attribute this increase primarily to the increased occurrence of a circulation pattern associated with transport of cold Arctic air into central Asia. Modelling studies ${ }^{9}$ have suggested that such an altered circulation pattern is attributable to declining sea-ice extent in the Barents and Kara seas. However, the authors find no evidence of increased wintertime cold temperature extremes over North America, despite the attention given to claims of such an increase ${ }^{3}$.

One concern with this study is that it is based on 35-year (and in some cases only 24-year) time series, which are quite short by climate standards. Horton and co-workers performed an extensive analysis to determine the statistical significance of the trends, but this establishes only that discernible changes occurred over the periods in question. As the authors note, the identified circulation trends may just reflect multi-decadal natural variability and cannot necessarily be associated with climate change. This is clearly an 
important issue to resolve. Other climate extremes, such as droughts and flooding, may be even more susceptible to circulation changes than are temperature extremes.

A better observational record of past changes in atmospheric circulation, over the previous century and possibly over even longer timescales - e.g. from ships' logbooks or climate proxies - would help put the recent changes in context. A better understanding of the mechanisms of climate variability is also needed to improve prediction capabilities. Finally, a better physical understanding of the expected atmospheric circulation response to climate change would provide hypotheses to test. In particular, can the most extreme predictions of circulation changes be constrained or excluded by the observational record? Unless progress is made on these fronts, we will continue to be surprised by deviations from the thermodynamic expectations of global warming.

Theodore G. Shepherd is at the Department of Meteorology, University of Reading, Reading RG6 6BB, UK.

e-mail: theodore.shepherd@reading.ac.uk

1. IPCC Climate Change 2013: The Physical Science Basis (eds Stocker, T. F. et al.) (Cambridge Univ. Press, 2013).

2. Horton, D. E. et al. Contribution of changes in atmospheric circulation patterns to extreme temperature trends. Nature, this issue.

3. Cohen J. et al. Recent Arctic amplification and extreme mid-latitude weather. Nature Geosci. 7, 627-637 (2014).

4. Screen, J. A. \& Simmonds, I. Amplified mid-latitude planetary waves favour particular regional weather extremes. Nature Climate Change 4, 704-709 (2014). 
5. Miralles, D. G., Teuling, A. J., van Heerwaarden, C. C. \& Vila-Guerau de Arellano, J. Megaheatwave temperatures due to combined soil desiccation and atmospheric heat accumulation. Nature Geosci. 7, 345-349 (2014).

6. Deser, C., Phillips, A. S., Alexander, M. A. \& Smoliak, B. V. Projecting North American climate over the next 50 years: uncertainty due to internal variability. J. Clim. 27, 22712296 (2014).

7. Barnes, E. A. Revisiting the evidence linking Arctic amplification to extreme weather in midlatitudes. Geophys. Res. Lett. 40, 4734-4739 (2014).

8. Shepherd, T. G. Atmospheric circulation as a source of uncertainty in climate change projections. Nature Geosci. 7, 703-708 (2014).

9. Mori, M., Watanabe, M., Shiogama, H., Inoue, J. \& Kimoto, M. Robust Arctic sea-ice influence of the frequent Eurasian cold winters in past decades. Nature Geosci. 7, 869-873 (2014).

Figure 1 | The European heat wave in 2003. Horton et al. ${ }^{2}$ report that this 2003 event was part of a long-term trend towards more anti-cyclonic summertime circulation regimes over Europe, which favour heat waves. 